\title{
Produção, composição do leite e constituintes sangüíneos de cabras alimentadas com diferentes volumosos
}

\author{
[Production, milk composition and blood parameters in goats fed different forages] \\ L.R. Ribeiro, J.C. Damasceno, U. Cecato, C.C. Jobim, G.T. Santos, \\ F.A.F. Macedo, L.G.P. Macedo \\ Departamento de Zootecnia - UEM \\ Av. Colombo, 5790 \\ 87020-900 - Maringá, PR
}

\begin{abstract}
RESUMO
Utilizaram-se nove cabras da raça Saanen, para estudar o efeito de dietas compostas por três diferentes fontes de volumosos, feno de alfafa, silagem de milho e feno de aveia, sobre a ingestão de matéria seca, produção e composição do leite e sobre os constituintes sangüíneos, glicose e uréia plasmáticas, em triplo quadrado latino $3 \times 3$. Os consumos de matéria seca e proteína bruta dos animais alimentados com feno de alfafa foram mais altos que os à base de silagem de milho $(\mathrm{P} \leq 0,05)$, e os que receberam feno de aveia consumiram mais constituintes da parede celular que os demais $(\mathrm{P} \leq 0,05)$. Não houve efeito $(\mathrm{P}>0,05)$ das dietas sobre a produção diária de leite $(\mathrm{kg} / \mathrm{dia})$, sobre os teores $(\%)$ de gordura, proteína, lactose e sólidos totais e sobre a contagem de células somáticas (cels/mlx1000). Os animais que consumiram feno de alfafa produziram maiores quantidades $(\mathrm{P} \leq 0,05)$ de proteína, gordura e lactose comparados àqueles que receberam dietas com silagem de milho. Não houve efeito das dietas sobre a concentração de glicose plasmática $(\mathrm{P}>0,05)$. Os resultados indicaram que a fonte de volumoso, em rações isoenergéticas e isoproteicas, afeta o desempenho dos animais pela alteração no consumo de MS e PB e produção dos constituintes do leite ( $\mathrm{kg} / \mathrm{dia})$.
\end{abstract}

Palavras-chave: cabra, feno de alfafa, feno de aveia, silagem de milho, consumo, constituintes do leite

\begin{abstract}
Nine Saanen dairy goats, consuming diets composed of three different sources of roughage (alfalfa hay, corn silage, and oat hay) were used to study the effect of those diets on the ingestion of dry matter (DM), on milk production, milk composition, and plasmatic glucose and urea levels. The experimental design was a triple latin square 3x3. The intakes of DM and crude protein by the animals fed on alfalfa hay were higher than those fed ration based on corn silage ( $\triangle \leq 0.05)$, while those receiving oat hay presented a higher intake of the cellular wall compared to the others $(P \leq 0.05)$. There was no percentual effect $(P>0.05)$ of the diets on the daily milk production and on the fat, protein, lactose, and total solids contents, and on the somatic cells count (SCC), but those cows that received diets with alfalfa hay produced higher amounts (g/day) (P $\leq 0.05)$ of protein, fat, and lactose than those that received diets with corn silage. There was no effect of the diets on the concentration of plasmatic glucose $(P>0.05)$. It can be concluded that the forage sources affect the animal performance from changes in both DM and CP intakes and production of milk components ( $\mathrm{kg} /$ day).
\end{abstract}

Keywords: goat, alfalfa hay, oat hay, corn silage, voluntary intake, milk composition

\section{INTRODUÇÃO}

O manejo alimentar determina em grande parte a produtividade de sistemas de produção de leite, no que diz respeito à quantidade produzida e à qualidade do produto final. Embora haja muitos trabalhos de pesquisa sobre o assunto em ruminantes, é necessário responder questões ainda não esclarecidas no que diz respeito à alimentação de cabras leiteiras (Bresslau et al., 1997). Pesquisas apontam efeitos de fontes e níveis de nutrientes sobre a produção e composição do leite de cabras.

Recebido em 5 de novembro de 2007

Aceito em 6 de outubro de 2008

E-mail: 1rribeiro@uem.br 
Damasceno et al. (1997) obtiveram aumento linear na produção de leite com incremento no nível de suplementação energética e protéica para cabras Saanen e Sampelayo et al. (1998), ao utilizarem diferentes fontes protéicas em rações contendo feno de alfafa como volumoso, relataram efeito sobre a degradação ruminal e sobre a produção e composição do leite.

Macedo et al. (2003) verificaram redução na produção de leite e na produção de gordura e proteína do leite, mas não encontraram efeito sobre os teores dos constituintes do leite, quando estudaram a inclusão da farinha de glúten de milho em rações de cabras leiteiras em substituição ao farelo de soja como fonte protéica. Torii et al. (2004) observaram efeito da fonte de volumoso sobre a composição dos ácidos graxos do leite quando estudaram diferentes volumosos em rações de cabras Saanen. Contudo, há situação em que não se observa efeito da dieta sobre a produção e composição do leite (Mouro et al., 2002) ou composição em gordura e proteína e qualidades organolépticas em derivados do leite (Soryal et al., 2004) de cabras leiteiras.

As rações completas fornecem a relação mais adequada entre volumoso e concentrado, evitando que o animal consuma proporção indesejada de alimentos. Observações experimentais indicam aumento de até $20 \%$ no consumo voluntário e, conseqüentemente, na produção de leite e no ganho de peso corporal, quando do uso de rações completas (Faria, 1993). Ribeiro et al. (1997) verificaram que, durante a produção ao longo do ano, a composição do leite de cabra varia quanto aos seguintes constituintes: proteína bruta, cinzas, gordura e lactose, sendo a variação desses dois últimos em razão do nível de produção.

Para cabras, os valores normais da contagem de células somáticas (CCS) são mais altos do que para vacas, 1.000 .00 e 750.000, respectivamente, considerando esses valores como máximos e não prejudiciais à saúde humana (Haenlein e Hinckley, 1998). Sung et al. (1999), ao estudarem a qualidade do leite entre raças caprinas leiteiras, entre elas a Saanen, encontraram diferenças significativas para a CCS e para California mastitis test (CMT) entre as raças estudadas. Também observaram alta correlação negativa entre CCS e teor de lactose no leite, e correlação positiva alta entre porcentagens de gordura, de proteína de sólidos totais e CCS.

O sangue faz a comunicação entre sistemas, garantindo-lhes equilíbrio hídrico e osmótico, mantendo o equilíbrio ácido-básico e regulação térmica. Formado pelas células sangüíneas (eritrócitos, leucócitos e trombócitos), plasma e soro, carreia nutrientes do trato digestório para os tecidos, e produtos finais do metabolismo celular para os órgãos, para utilização ou excreção, funcionando como meio de transporte de substâncias nutritivas, gases, excretas, hormônios, enzimas, anticorpos e sais. O plasma contém de 91 a $92 \%$ de água. É nele que estão suspensas todas as células, dependendo do volume da espécie animal e do tipo de alimentação. O plasma de caprinos é incolor ou ligeiramente amarelado. A cor resulta principalmente da variação da concentração do pigmento denominado bilirrubina, embora $\mathrm{o}$ caroteno e outros pigmentos sejam fatores que também interferem em sua cor. Entre as substâncias que constituem o plasma, encontramse as orgânicas, os nutrientes como a glicose, e as nitrogenadas de excreção, como a uréia, ácido úrico e creatina.

A concentração de glicose circulante nos ruminantes adultos é substancialmente mais baixa do que em não ruminantes. $\mathrm{Na}$ glândula mamária, a glicose e a galactose sangüíneas são transformadas em lactose pela ligação entre o carbono 1 da galactose com o carbono 4 da glicose. Conhecida como o "açúcar do leite", a lactose é produzida pela maioria dos mamíferos, sendo o leite a fonte primária desta (Champe e Harvey, 1994).

Assumindo-se que o uso de fontes distintas de volumosos em dietas isoprotéicas e isoenergéticas seria uma estratégia para maximizar a produção e a composição do leite de cabras leiteiras, o presente experimento teve como objetivo avaliar dietas compostas por três fontes de volumosos, feno de alfafa, feno de aveia e silagem de milho, nas seguintes respostas dos animais: consumo voluntário, produção de leite, composição química do leite, contagem de células somáticas e concentrações plasmáticas de glicose e uréia. 


\section{MATERIAL E MÉTODOS}

$\mathrm{O}$ experimento foi realizado entre dezembro de 1999 e fevereiro de 2000, utilizando-se nove cabras da raça Saanen, de segunda lactação, com peso vivo médio de $50 \mathrm{~kg}$, selecionadas e agrupadas de acordo com o nível de produção e peso corporal, e distribuídas em delineamento experimental triplo quadrado latino $(3 \times 3)$, resultando em nove repetições por tratamento.

As ordenhas foram realizadas pela manhã (8h) e à tarde (16h). Após a ordenha da manhã, os animais retornavam às baias, onde tinham acesso ao alimento por cerca de uma hora e, posteriormente, eram conduzidos ao solário, onde permaneciam até $11 \mathrm{~h} 30 \mathrm{~min}$, para então retornarem às respectivas baias. Os tratamentos consistiram de três dietas formuladas com feno de alfafa ou feno de aveia ou silagem de milho (Tab. 1). A relação volumoso:concentrado foi de $1: 1$, com base nas matéria seca (MS).

Os fenos foram picados em peneira com crivos de $5 \mathrm{~mm}$. Os volumosos foram fornecidos aos animais misturados ao restante dos ingredientes das respectivas dietas, como dieta total. Os percentuais de fibra em detergente neutro (FDN), fibra em detergente ácido (FDA) e proteína bruta (PB) são apresentados na Tab. 2.

Os animais foram alimentados duas vezes ao dia, às $8 \mathrm{~h} 30 \mathrm{~min}$ e às $16 \mathrm{~h} 30 \mathrm{~min}$. A quantidade de MS ofertada representou $5 \%$ do peso vivo (PV), acrescida em $10 \%$, com o objetivo de maximizar o consumo voluntário. Antes da alimentação da manhã, retiravam-se, pesavam-se e amostravamse as sobras do dia anterior e os alimentos fornecidos, permitindo-se a determinação do consumo de alimento diário, individualmente.

O experimento consistiu de três períodos de 21 dias, sendo 14 dias de adaptação e sete dias de coleta de dados das seguintes variáveis: consumo, produção e composição do leite e parâmetros sangüíneos, uréia e glicose plasmáticas. Para o consumo de alimentos e produção de leite, consideraram-se todos os sete dias da fase de coleta. A produção de leite foi obtida diariamente a partir das ordenhas da manhã e tarde, individualmente. Para a composição química do leite, foram coletadas amostras (20ml/animal/dia) nas ordenhas da manhã e tarde em dias intercalados, totalizandose quatro amostras. Para os parâmetros sangüíneos, coletaram-se amostras de sangue apenas no último dia da fase de coleta, após a ordenha da tarde. Essas amostras, coletadas com a utilização de seringas descartáveis de $10 \mathrm{ml}$, foram transferidas para tubos de ensaio, para posterior centrifugação sob refrigeração.

As amostras dos alimentos e sobras, secas em estufa de ventilação forçada de ar a $55^{\circ} \mathrm{C}$ por 72 horas, foram moídas em moinho de facas (para a silagem) ou moinho de martelos (outras rações) com peneira com crivos de $1 \mathrm{~mm}$ de diâmetro para posterior determinação dos teores de MS, PB, FDN e FDA, segundo Silva (1990).

Tabela 1. Composição (\%, base na MS) das dietas experimentais, contendo diferentes volumosos fornecidas a cabras leiteiras da raça Saanen, para avaliação do consumo de MS e qualidade do leite

\begin{tabular}{lccc}
\hline Ingrediente & \multicolumn{3}{c}{ Tratamento } \\
\cline { 2 - 4 } & Dieta com alfafa & Dieta com aveia & Dieta com silagem \\
\hline Feno de alfafa & 48,11 & - & - \\
Feno de aveia & - & 50,00 & - \\
Silagem de milho & - & - & 50,00 \\
Farelo de soja & 20,74 & 25,75 & 28,00 \\
Milho grão moído & 29,26 & 18,41 & 16,30 \\
Uréia & - & - & 0,97 \\
Óleo de soja & 0,30 & 3,00 & - \\
Calcário calcítico & 0,14 & 1,65 & 2,83 \\
Fosfato bicálcico & 1,44 & 1,20 & 1,90 \\
Nutrientes* & & & 18,00 \\
Proteína digestível (\%) & 18,00 & 18,00 & 3.100 \\
Energia digestível (Kcal) & 3.100 & 3.100 & 1,150 \\
Cálcio (\%) & 1,150 & 1,150 & 0,600 \\
Fósforo (\%) & 0,600 & 0,600 & \\
\hline
\end{tabular}

Fonte: Nutrient... (1981). MS: matéria seca. 
As amostras de leite foram armazenadas à temperatura ambiente em um recipiente plástico, de aproximadamente $40 \mathrm{ml}$, para as seguintes análises: proteína bruta, gordura, lactose, sólidos totais e contagem de células somáticas (CCS). Estas análises foram realizadas em analisador Bentley 2000, em que a radiação infravermelha refletida a partir dos constituintes da amostra são transformadas em impulsos elétricos, detectados por um fotomultiplicador.

Tabela 2. Valores médios (\% na MS) de fibra em detergente neutro (FDN), fibra em detergente ácido (FDA) e proteína bruta (PB) nas dietas, contendo diferentes volumosos para alimentar cabras leiteiras Saanen e avaliar a ingestão de MS e qualidade do leite

\begin{tabular}{lccc}
\hline Componente $^{1}$ & \multicolumn{3}{c}{ Fonte de volumoso } \\
\cline { 2 - 4 } & Feno de alfafa & Silagem de milho & Feno de aveia \\
\hline FDN (\%) & 21,51 & 31,18 & 38,87 \\
FDA (\%) & 14,61 & 22,00 & 22,70 \\
PB (\%) & 20,93 & 19,14 & 15,72 \\
\hline
\end{tabular}

MS: matéria seca.

${ }^{1}$ Valores obtidos no Laboratório de Nutrição Animal DZO/UEM.

As amostras de sangue, inicialmente, foram coaguladas e em seguida centrifugadas a $4^{\circ} \mathrm{C}$ a $2.500 \mathrm{rpm}$ durante $10 \mathrm{~min}$. Após, o sobrenadante foi transferido para outro tubo em que foram realizadas as análises de uréia e glicose. Os teores de glicose $(\mathrm{mg} / \mathrm{dl})$ e uréia $(\mathrm{mg} / \mathrm{dl})$ plasmáticos foram determinados em um analisador Vitalab Selectra-2, utilizando-se os métodos enzimáticos Trinder (glicose-oxidase), para glicose, e GIDH, para uréia.

Os resultados das variáveis estudadas foram submetidos à análise de variância, e as médias foram comparadas pelo teste Tukey, segundo o modelo estatístico:

$\mathrm{Y}_{\mathrm{ijkl}}=\mu+\mathrm{QL}_{\mathrm{i}}+\mathrm{D}_{\mathrm{j}}+\mathrm{P}_{\mathrm{k}}+\mathrm{D}_{\mathrm{i}} \mathrm{x} \mathrm{P}_{\mathrm{k}}+\varepsilon_{\mathrm{ijkl}}$, em que:

$\mathrm{Y}_{\mathrm{ijkl}}=$ observação referente ao animal 1 no período

$\mathrm{k}$ recebendo dieta $\mathrm{j}$ dentro do quadrado latino i;

$\mu=$ constante inerente a todas as observações;

$\mathrm{QL}_{\mathrm{i}}=$ efeito do quadrado latino i;

$\mathrm{D}_{\mathrm{j}}=$ efeito da dieta $\mathrm{j}$;

$\mathrm{P}_{\mathrm{k}}=$ efeito do período $\mathrm{k}$;

$\mathrm{D}_{\mathrm{i}} \mathrm{xP}_{\mathrm{k}}=$ efeito da interação da dieta $\mathrm{j}$ com o período $\mathrm{k}$;

$\varepsilon_{\mathrm{ijkl}}=$ erro aleatório associado a cada observação.

Para a análise dos dados, foi utilizado o programa estatístico SAEG (Sistema ..., 1997).

\section{RESULTADOS E DISCUSSÃO}

Os resultados de consumo de MS, PB e constituintes da parede celular encontram-se na Tab. 3. Quando expresso em quilogramas por dia, verificou-se que os consumos de MS, de FDA e de PB pelos animais alimentados com feno de alfafa sempre foram mais altos que os alimentados com ração à base de silagem de milho $(\mathrm{P} \leq 0,05)$, enquanto aqueles que receberam feno de aveia apresentaram maior consumo dos constituintes da parede celular, comparados aos que receberam silagem de milho (FDN e FDA) e feno de alfafa (FDN) $(\mathrm{P} \leq 0,05)$. Quando expressos em percentagem do peso corporal, os animais que receberam feno de alfafa superaram $(\mathrm{P} \leq 0,05)$ os demais no consumo de MS e PB. Para os constituintes da parede celular, o comportamento foi o mesmo que o expresso em quilogramas por dia.

Os consumos observados no presente experimento foram mais elevados que os encontrados por Macedo et al. (2003). A superioridade do feno de alfafa em relação às demais fontes de volumosos para a variável consumo já era esperada, uma vez que se trata de forragem de alto valor nutricional, com altos teores de PB e baixos em FDN e FDA, e elevada digestibilidade.

Os resultados indicaram, provavelmente, que o mecanismo de controle de consumo voluntário que estaria agindo, preferencialmente, para as dietas com feno de alfafa ou aveia seria o preenchimento ruminal, observando-se que os consumos de FDN e FDA para as duas dietas foram semelhantes (Van Soest, 1994). Para a dieta com silagem de milho, outros mecanismos estariam atuando conjuntamente ao preenchimento ruminal, como, por exemplo, qualidade da silagem em relação à presença de mofos, outros fatores indesejáveis e composição em ácidos graxos voláteis (Predicting..., 1987), resultando em menor consumo de MS e constituintes da parede celular. 
A partir dos valores da composição das dietas em relação aos ingredientes utilizados e aos teores de PB e constituintes da parede celular, verificase que a utilização dos diferentes volumosos resultou em rações com teores distintos dos referidos constituintes. Esse fato condicionou, provavelmente, a resposta dos animais, comprometendo, em parte, a hipótese inicial, em que se previa rações isoprotéicas e isoenergéticas. Outro fato que merece consideração é que os teores de energia fermentável e proteína degradável no rúmen, não determinados no presente experimento, foram diferentes nas dietas; parte da energia de algumas dietas foi representada por óleo vegetal (dietas com fenos de alfafa e aveia) e por ácidos graxos voláteis (dieta com silagem), ambos não fermentáveis. Quanto à fração protéica, sabe-se que há diferenças consideráveis para a degradabilidade ruminal dependendo da fonte, o que pode significar diferenças consideráveis entre dietas para esse atributo.

A diferença no consumo de MS observada entre os fenos de alfafa e aveia foi devido, principalmente, ao menor teor de FDN da alfafa e/ou melhor qualidade da FDN neste alimento ou outros mecanismos pós-ingestivos. O maior consumo de $\mathrm{PB}$ pelos animais que receberam feno de alfafa foi o resultado do maior teor de $\mathrm{PB}$ da ração, associado ao maior consumo de MS.

Tabela 3. Médias do consumo (kg/dia e \%PV) de matéria seca (MS), fibra em detergente neutro (FDN), fibra em detergente ácido (FDA), e proteína bruta (PB) das dietas experimentais, por cabras Saanen alimentadas com ração, contendo diferentes volumosos, para avaliação da ingestão de MS e qualidade do leite

\begin{tabular}{lccccc}
\hline \multirow{2}{*}{ Variável } & \multicolumn{3}{c}{ Fonte de volumoso } & \multirow{2}{*}{ P } & \multirow{2}{*}{ CV $(\%)$} \\
\cline { 2 - 4 } & $\begin{array}{c}\text { Feno de } \\
\text { alfafa }\end{array}$ & $\begin{array}{c}\text { Silagem de } \\
\text { milho }\end{array}$ & $\begin{array}{c}\text { Feno de } \\
\text { aveia }\end{array}$ & & \\
\hline Consumo de MS (kg/dia) & $2,60 \mathrm{~A}$ & $1,84 \mathrm{~B}$ & $2,05 \mathrm{AB}$ & 0,0113 & 22,29 \\
Consumo FDA (kg/dia) & $0,341 \mathrm{~A}$ & $0,122 \mathrm{~B}$ & $0,410 \mathrm{~A}$ & 0,0000 & 26,63 \\
Consumo FDN (kg/dia) & $0,559 \mathrm{~B}$ & $0,474 \mathrm{~B}$ & $0,772 \mathrm{~A}$ & 0,0012 & 25,09 \\
Consumo de PB (kg/dia) & $0,545 \mathrm{~A}$ & $0,413 \mathrm{~B}$ & $0,323 \mathrm{~B}$ & 0,0014 & 24,45 \\
\hline Consumo MS (\%PV/dia) & $5,54 \mathrm{~A}$ & $3,74 \mathrm{~B}$ & $3,91 \mathrm{~B}$ & 0,0015 & 21,53 \\
Consumo FDA (\%PV/dia) & $0,727 \mathrm{~A}$ & $0,248 \mathrm{~B}$ & $0,781 \mathrm{~A}$ & 0,0000 & 25,56 \\
Consumo FDN (\%PV/dia) & $1,19 \mathrm{AB}$ & $0,9593 \mathrm{~B}$ & $1,5092 \mathrm{~A}$ & 0,0053 & 24,96 \\
Consumo PB (\%PV/dia) & $1,16 \mathrm{~A}$ & $0,8427 \mathrm{~B}$ & $0,6158 \mathrm{~B}$ & 0,0002 & 23,64 \\
\hline
\end{tabular}

PV: peso vivo; P: probabilidade de significância; $\mathrm{CV}$ : coeficiente de variação.

Médias seguidas de letras diferentes, na linha, diferem entre si pelo teste Tukey $(\mathrm{P} \leq 0,05)$.

A dieta contendo feno de alfafa apresentou-se mais densa em relação à dieta com feno de aveia e silagem. Sabe-se que partículas mais densas têm maior probabilidade de escape do rúmenretículo, tendo provavelmente favorecido maior consumo de MS pelos animais que receberam o feno de alfafa na dieta.

Os resultados de produção e composição do leite estão apresentados na Tab. 4. Não houve efeito $(\mathrm{P}>0,05)$ das dietas na produção diária de leite e nos teores de gordura, proteína, lactose e sólidos totais do leite, sendo as médias iguais a $2,5 \mathrm{~kg} / \mathrm{dia}, \quad 2,8 \%, \quad 2,9 \%, \quad 4,2 \%$ e $10,1 \%$, respectivamente. Estes valores estão próximos aos relatados por Damasceno et al. (1997) e mais baixos que os de Chornobai (1998) e Macedo et al. (2003). Segundo Sung et al. (1999), as médias encontradas para a raça Saanen foram 3,3\% de proteína, 2,6\% de gordura e 4,6\% lactose.
A produção diária ( $\mathrm{g} /$ dia) dos constituintes do leite variou em função das dietas avaliadas. Os animais que receberam dietas contendo feno de alfafa produziram quantidades mais elevadas $(\mathrm{P} \leq 0,05)$ de proteína, gordura e lactose em relação àqueles que receberam dietas com silagem de milho. $\mathrm{O}$ feno de aveia não diferiu das demais fontes de volumosos $(\mathrm{P}>0,05)$. Esse comportamento é semelhante ao observado para o consumo, evidenciando que a maior ingestão de MS resultou em incremento na produção dos constituintes do leite, o que confirma as observações de Damasceno et al. (1997) que relataram aumento na quantidade de proteína, mas não de gordura, com aumento no consumo de energia pelos animais. Medeiros et al. (1994) afirmaram que os maiores consumos de energia e proteína têm como conseqüências o aumento de proteína no leite. 
Tabela 4. Valores médios da produção de leite $(\mathrm{kg} / \mathrm{dia})$, teores $(\%)$ e produção $(\mathrm{g} / \mathrm{dia})$ de gordura, proteína, lactose, sólidos totais e contagem de células somáticas (CCS) do leite de cabras Saanen, alimentadas com ração contendo diferentes volumosos, para avaliação da ingestão de MS e qualidade do leite

\begin{tabular}{|c|c|c|c|c|c|}
\hline \multirow{2}{*}{ Variável } & \multicolumn{3}{|c|}{ Fonte de volumoso } & \multirow[b]{2}{*}{$\mathrm{P}$} & \multirow[b]{2}{*}{$\mathrm{CV}$} \\
\hline & $\begin{array}{l}\text { Feno de } \\
\text { alfafa }\end{array}$ & $\begin{array}{l}\text { Silagem de } \\
\text { milho }\end{array}$ & $\begin{array}{c}\text { Feno de } \\
\text { aveia }\end{array}$ & & \\
\hline Produção de leite (kg/dia) & 2,85 & 2,22 & 2,43 & 0,0683 & 21,60 \\
\hline Gordura $(\%)$ & 2,65 & 2,71 & 2,88 & $\mathrm{NS}^{(3)}$ & 19,20 \\
\hline Proteína (\%) & 2,84 & 2,88 & 2,97 & NS & 10,16 \\
\hline Lactose $(\%)$ & 4,28 & 4,13 & 4,09 & NS & 4,60 \\
\hline Sólidos Totais (\%) & 10,13 & 10,04 & 10,22 & NS & 10,00 \\
\hline Gordura (g/dia) & $74,94 \mathrm{~A}$ & $59,01 \mathrm{~B}$ & 63,40 A B & 0,0470 & 19,45 \\
\hline Proteína (g/dia) & $80,89 \mathrm{~A}$ & $62,98 \mathrm{~B}$ & 69,17 A B & 0,0230 & 17,50 \\
\hline Lactose (g/dia) & $121,60 \mathrm{~A}$ & $91,68 \mathrm{~B}$ & $101,10 \mathrm{~A} \mathrm{~B}$ & 0,0501 & 22,99 \\
\hline Sólidos Totais (g) & 287,85 & 221,62 & 239,81 & 0,0570 & 22,15 \\
\hline $\mathrm{CCS}(\mathrm{cel} / \mathrm{ml} \times 1000)$ & $1.947,08$ & $1.758,81$ & $1.813,86$ & NS & 40,35 \\
\hline
\end{tabular}

MS: matéria seca, P: probabilidade de significância; CV: coeficiente de variação; NS: não significativo. Médias seguidas de letras diferentes, na linha, diferem entre si pelo teste Tukey $(\mathrm{P} \leq 0,05)$.

Embora não tenha sido evidenciado o efeito dos tratamentos na produção e na composição do leite ao serem consideradas separadamente, pode-se supor que a dieta contendo feno de alfafa resultará em maiores benefícios industrial e econômico (Fekadu et al., 2005) uma vez que as quantidades produzidas de gordura e proteína foram maiores neste tratamento (Bresslau et al., 1997; Sung et al., 1999).

Os valores de CCS são apresentados na Tab. 4. As médias variaram de 1.758 .810 a 1.947 .080 células $/ \mathrm{ml}$ de leite, sem apresentar diferenças $(P>0,05)$ entre os tratamentos. Estes valores são ligeiramente mais altos que os encontrados por Damasceno et al. (1997) e Zeng e Escobar (1995).

Hussain et al. (1996) relataram que a CCS é maior para animais que consomem alimentos de má qualidade; isso indica não haver diferenças importantes entre dietas no presente experimento que resultassem em alterações importantes na CCS.

As concentrações de uréia e glicose plasmáticas são apresentadas na Tab. 5. Animais que receberam dietas com silagem de milho apresentaram concentração de uréia plasmática $58 \%$ mais alta $(\mathrm{P} \leq 0,05)$ que animais que receberam feno de aveia, enquanto o tratamento com feno de alfafa não diferiu dos demais $(\mathrm{P}>0,05)$. Estes resultados são devidos, provavelmente, aos maiores teores de PB das dietas compostas com feno de alfafa e silagem de milho em relação àquela com feno de aveia, e também por estas dietas apresentarem fontes protéicas de elevada degradabilidade ruminal, principalmente para a dieta com silagem (Petit, 1994; Valadares Filho, 1994). A dieta com feno de alfafa apresentou maior percentual de PB, tendo sido maior em $9,4 \%$ do que a dieta contendo silagem de milho e $33,1 \%$ maior que a dieta com feno de aveia. Essas diferenças ocorreram em razão de terem sido utilizados valores de composição dos alimentos tabelados (Nutrient..., 1981) para a formulação das dietas.

Os resultados da presente pesquisa foram semelhantes e/ou mais elevados que os encontrados por Mundim et al. (2007), para cabras Saanen lactantes.

Tabela 5. Valores médios, em $\mathrm{mg} / \mathrm{dl}$ de uréia e glicose no plasma sangüíneo de cabras Saanen, alimentadas com ração contendo diferentes volumosos: feno de alfafa, silagem de milho, feno de aveia

\begin{tabular}{lccccc}
\hline Variáveis & Feno de alfafa & Silagem de milho & Feno de aveia & P & CV \\
\hline Uréia $(\mathrm{mg} / \mathrm{dl})$ & $94,22 \mathrm{AB}$ & $117,22 \mathrm{~A}$ & $74,22 \mathrm{~B}$ & 0,005 & 24,66 \\
Glicose $(\mathrm{mg} / \mathrm{dl})$ & 51,33 & 43,78 & 42,89 & 0,230 & 23,81 \\
& & & & \\
\hline
\end{tabular}

P: probabilidade de significância; CV: coeficiente de variação.

Médias seguidas de letras diferentes, na linha, diferem entre si pelo teste Tukey $(\mathrm{P} \leq 0,05)$. 
Como descrito por Van Soest (1994), alto nível de nitrogênio na dieta provoca maior fluxo desse nutriente para os tecidos e para o fígado, e desse órgão para o sangue. Swenson (1996) relata que o metabolismo protéico no ruminante envolve a participação do ciclo da uréia entre o rúmen e o sangue, demonstrando que ovinos alimentados com dieta de alto teor protéico apresentam maior concentração plasmática de uréia. A maior concentração de uréia circulante no sangue das cabras alimentadas com a dieta contendo silagem de milho pode ser atribuída ao maior aporte de nitrogênio disponível, ou talvez à falta de sincronização entre os esqueletos de carbono e o nitrogênio utilizados pelos microrganismos durante suas sínteses.

Não houve efeito dos tratamentos sobre a concentração de glicose plasmática $(\mathrm{P}>0,05)$. Tal fato pode ser devido ao procedimento de amostragem, em que as coletas de sangue eram feitas apenas uma vez ao dia, não considerando as variações ao longo do dia, principalmente amostragens freqüentes após os momentos de maior ingestão de alimentos. Como há mecanismos que garantem o rápido equilíbrio nas concentrações de glicose sangüínea, as amostragens efetuadas refletiram nada mais que concentrações em uma fase estável. Pode-se supor que a concentração de glicose nos animais alimentados com feno de alfafa, cujo consumo de MS foi o maior, seria mais alto nos momentos após os picos de consumo. Outro fato a ser considerado é que a formulação das dietas ocorreu em padrões de fermentação ruminal distintos, o que provavelmente resultaria em substratos glicogênicos também distintos. A partir dessas considerações, pode-se inferir que tal procedimento de amostragem não seria indicado, pois não refletiu a dinâmica da concentração de glicose plasmática ao longo do dia, não permitindo detectar diferenças mesmo numa condição em que o consumo de MS foi consideravelmente distinto.

\section{CONCLUSÕES}

A fonte de volumoso modula o desempenho animal por meio do consumo de matéria seca da dieta e produção dos constituintes do leite, mas não altera os teores dos constituintes do leite e glicose sangüínea. Dietas contendo silagem de milho elevam os níveis de uréia plasmática, e o feno de alfafa é a fonte de volumoso que promove melhor desempenho animal.

\section{REFERÊNCIAS BIBLIOGRÁFICAS}

BRESSLAU, S.; FONSECA, M.F.A.C.; BORGES, C.H.P. Caracterização dos fornecedores de leite de cabra da QueijariaEscola de Nova Friburgo, RJ. In: REUNIÃO ANUAL DA SOCIEDADE BRASILEIRA DE ZOOTECNIA, 34., 1997, Juiz de Fora. Anais... Juiz de Fora: SBZ, 1997, p.322-324.

CHAMPE, P.C.; HARVEY, R.A. 1994. Lippincott's illustrated reviews: biochemistry. 2.ed. Philadelphia: J.B. Lippincott, 1994. 446p.

CHORNOBAI, C.A.M. Caracterização físicoquímica de leite in natura de cabras cruza Saanen, ao longo do período de lactação. 1998. 100f. Dissertação (Mestrado) - Universidade Estadual de Maringá, Maringá.

DAMASCENO, J.C.; FERREIRA, A.C.D.; GEAHL, S.E. Responses of the dairy goats supplemented with different levels of concentrate. J. Dairy Sci., v.80, suppl.1, p.462, 1997.

FARIA, V.P. Rações completas para vacas em lactação, In: PEIXOTO, A.M.; MOURA, J.C.; FARIA, V.P. Confinamento de bovinos leiteiros. Piracicaba: FEALQ, 1993. p.229-244.

FEKADU, B.; SORYAL, K.; ZENG, S. et al. Changes in goat milk composition during lactation and their effect on yield and quality of hard and semi-hard cheeses. Small Rumin. Res., v.59, p.55-63, 2005.

HAENLEIN, G.F.W.; HINCKLEY, L.S. Goat Management - Goat milk somatic cell count situation in the United States. 1998, Disponível em:

$<$ http://bluehen.ags.udel.edu/deces/goatmgt/gm11.htm>. Acessado em: 14 set. 1998.

HUSSAIN, Q.; HAVREVOLL, Ø.; EIK, L.O. Effect of type roughage on feed intake, milk yield and body condition of pregnant goats. Small Rumin. Res., v.22, p.131-139, 1996.

MACEDO, L.G.P.; DAMASCENO, J.C.; MARTINS, E.N. et al. Substituição do farelo de soja pela farinha de glúten de milho na alimentação de cabras leiteiras. Rev. Bras. Zootec., v.32, p.992-1001, 2003. 
MEDEIROS, L.P.; GIRÃO, R.N.; GIRÃO, E.S. et al. Caprinos: princípios básicos para sua exploração. Teresina, PI: Embrapa Caprinos, 1994. 177p.

MOURO, G.F.; BRANCO, A.F.; MACEDO, F.A.F. et al. Substituição do milho pela farinha de mandioca de varredura em dietas de cabra em lactação: produção e composição do leite e digestibilidade dos nutrientes. Rev. Bras. Zootec., v.31, p.475-483, 2002.

MUNDIM, A.V.; COSTA, A.S.; MUNDIM, S.A.P. et al. Influência da ordem de lactação no perfil bioquímico sangüíneo de cabras da raça Saanen. Arq. Bras. Med. Vet. Zoot., v.59, p.306312, 2007.

NUTRIENT requirements of goats. Washington, DC.: National Academy of Sciences, 1981.91p.

PETIT, H.V. Forage quality and its limiting factors for meat production. In: SIMPÓSIO INTERNACIONAL DE PRODUÇÃO DE RUMINANTES E REUNIÃO ANUAL DA SOCIEDADE BRASILEIRA DE ZOOTECNIA, 31., 1994, Maringá. Anais... Maringá: SBZ, 1994. p.61-80.

PREDICTING feed intake of food-producing animals. Washington, DC.: National Academy of Sciences, 1987. 85p.

RIBEIRO, A.C.; PRATA, L.F.; BARBIERI, M.R. et al. Variação da composição do leite de cabra ao longo do ano, em um criatório da região sudeste do Brasil. In: REUNIÃO ANUAL DA SOCIEDADE BRASILEIRA DE ZOOTECNIA, 34., 1997, Juiz de Fora. Anais... Juiz de Fora: SBZ, 1997. p.331-333.

SAMPELAYO, M.R.; AMIGO, L.; ARES, J.L. et al. The use of diets with different protein sources in lactating goats: composition of milk and its suitability for cheese production. Small Rumin. Res., v.31, p.37-43, 1998.
SILVA, D.J. Análise de alimentos: métodos químicos e biológicos. Viçosa: UFV, 1990. 165p.

SISTEMA para análises estatísticas - SAEG. Versão 7.1. Viçosa: UFV, 1997. 150p.

SORYAL, K.A.; ZENG, S.S.; MIN, B.R. et al. Effect of feeding treatments and lactation stages on composition and organoleptic quality of goat milk Domiati cheese. Small Rumin. Res., v.52, p.109-116, 2004.

SUNG, Y.Y., WU, T.I.; WANG, P.H. Evaluation of milk quality of Alpine, Nubian, Saanen and Toggenburg breeds in Taiwan. Small Rumin. Res., v.33, p.17-23, 1999.

SWENSON, M.J. Propriedades fisiológicas e constituintes químicos e celulares do sangue. In: SWENSON, M.J.; REECE, W.O. Dukes fisiologia dos animais domésticos. 11.ed. Rio de Janeiro: Guanabara Koogan, 1996. p.19-43.

TORII, M.S.; DAMASCENO, J.C.; RIBEIRO, L.R. et al. Physical-chemical characteristics and fatty acids composition in dairy goat milk in response to roughage diet. Braz. Arch. Biol. Technol., v.47, p.903-909, 2004.

VALADARES FILHO, S.C. Utilização da técnica in situ para avaliação dos alimentos. In: SIMPÓSIO INTERNACIONAL DE PRODUÇÃO DE RUMINANTES E REUNIÃO ANUAL DA SOCIEDADE BRASILEIRA DE ZOOTECNIA, 31., 1994, Maringá. Anais... Maringá: SBZ, 1994. p.95-118.

VAN SOEST, P.J. Nutritional ecology of the ruminant. Corvallis: O\&B, 1994. 475p.

ZENG, S.S.; ESCOBAR, E.N. Effect of parity and milk production on somatic cell count, standard plate count and composition of goat milk. Small Rumin. Res., v.17, p.269-274, 1995. 